\title{
Mineralocorticoid receptor in cardiovascular diseases - clinical trials and mechanistic insights
}

\author{
Johann Bauersachs ${ }^{1}$ and Natalie López Andrés ${ }^{2}$ \\ ${ }^{1}$ Medizinische Hochschule Hannover \\ ${ }^{2}$ Navarrobiomed
}

July 4, 2021

\begin{abstract}
Aldosterone binds to the mineralocorticoid receptor (MR), a transcription factor of the nuclear receptor family, present in the kidney and in various other non-epithelial cells including the heart and the vasculature (Cannavo et al., 2018). Indeed, extra-renal pathophysiological effects of this hormone have been characterized, extending its actions to the cardiovascular (CV) system (Messaoudi et al., 2012). A growing body of clinical and pre-clinical evidence suggests that MR activation plays an important pathophysiological role in CV remodeling by promoting cardiac hypertrophy, fibrosis, arterial stiffness, as well as in inflammation and oxidative stress (Bauersachs et al., 2015). The following review article outlines the role of MR in CV disease with a focus on myocardial remodeling and heart failure (HF) including clinical trials as well as cellular and animal studies.
\end{abstract}

\section{Mineralocorticoid receptor in cardiovascular diseases -}

clinical trials and mechanistic insights

Johann Bauersachs ${ }^{1}$, Natalia López-Andrés ${ }^{2}$

1 Department of Cardiology and Angiology, Hannover Medical School, Hannover, Germany

2 Cardiovascular Translational Research. Navarrabiomed (Miguel Servet Foundation), Instituto de Investigación Sanitaria de Navarra (IdiSNA), Complejo Hospitalario de Navarra (CHN), Universidad Pública de Navarra (UPNA), Pamplona. Spain

Corresponding authors:

Prof. Dr. med. Johann Bauersachs

Department of Cardiology and Angiology, Medical School Hannover

Carl-Neuberg-Straße 1, 30625 Hannover, Germany

Phone: +49 511 532-3841

Fax : +49 $511532-5412$

bauersachs.johann@mh-hannover.de

Or

Natalia López Andrés, PhD

Cardiovascular Translational Research. Navarrabiomed (Miguel Servet Foundation)

C/Irunlarrea 3, 31008, Pamplona. Spain 
Phone: $++(34) 848428539$

natalia.lopez.andres@navarra.es

Aldosterone binds to the mineralocorticoid receptor (MR), a transcription factor of the nuclear receptor family, present in the kidney and in various other non-epithelial cells including the heart and the vasculature (Cannavo et al., 2018). Indeed, extra-renal pathophysiological effects of this hormone have been characterized, extending its actions to the cardiovascular (CV) system (Messaoudi et al., 2012). A growing body of clinical and pre-clinical evidence suggests that MR activation plays an important pathophysiological role in CV remodeling by promoting cardiac hypertrophy, fibrosis, arterial stiffness, as well as in inflammation and oxidative stress (Bauersachs et al., 2015). The following review article outlines the role of MR in CV disease with a focus on myocardial remodeling and heart failure (HF) including clinical trials as well as cellular and animal studies.

\section{Clinical studies}

HF with reduced ejection fraction

Several large randomized placebo-controlled clinical trials provided the basis for MR antagonists (MRAs) as an essential treatment in patients with $\mathrm{HF}$ with reduced ejection fraction (HFrEF) and for their class I recommendation in current HF treatment guidelines (Ponikowski et al., 2016; Berliner et al., 2020; Bozkurt et al., 2021).

The RALES trial (Randomized Aldactone Evaluation Study) was the first study demonstrating that the addition of spironolactone to the standard therapy improved mortality and morbidity in patients with advanced HFrEF (NYHA class III-IV) (Pitt et al., 1999). These results were extended by the EPHESUS trial (Eplerenone Post-Acute Myocardial Infarction Heart Failure Efficacy and Survival Study): in patients with HF after myocardial infarction (MI), the MRA eplerenone, started between day 3 and 14 after MI, in addition to optimal standard therapy, significantly reduced mortality and HF hospitalizations. Earlier eplerenone administration (3-7 days) was associated with more beneficial outcomes compared with later (7-14 days) initiation after acute MI (Pitt et al., 2003). The EMPHASIS-HF trial (Eplerenone in Mild Patients Hospitalization And Survival Study in Heart Failure) expanded these findings, showing that eplerenone treatment in addition to standard therapy promoted a highly significant reduction in mortality and HF hospitalizations in patients with NYHA class II HFrEF (Zannad et al., 2011). However, the clinical uptake of MRAs in the treatment of HFrEF have been limited for a long time by the risk of hyperkalemia conferred by combined therapy with an ACE inhibitor, especially in patients with diabetes mellitus and/or chronic kidney disease (Zannad et al., 2012; Agarwal et al., 2021).

More recently, the novel non-steroidal selective MRA, finerenone, also demonstrated beneficial effects in HFrEF patients. In the ARTS-HF trial (Mineralocorticoid Receptor Antagonist Tolerability Study-Heart Failure), finerenone was well tolerated and decreased NT-proBNP levels to a similar extent as eplerenone in HFrEF patients with diabetes mellitus and/or chronic kidney disease and requiring hospitalization (Filippatos et al., 2016). A pre-specified composite clinical endpoint numerically occurred less frequently with finerenone. ARTS-HF was the first clinical trial to compare finerenone with eplerenone in patients with worsening HFrEF at risk for hyperkalemia. In such vulnerable population, finerenone was as effective as steroidal MRAs but was safer in patients with chronic kidney disease (Pei et al., 2018).

\section{HF with preserved ejection fraction}

The prevalence of HF with preserved ejection fraction (HFpEF) is increasing, mainly due to the aging populations, however, mortality remains unchanged. HFpEF, also referred to as diastolic HF, is a clinical entity characterized by signs and symptoms of HF with a normal or low-to-normal left ventricular (LV) ejection fraction. Clinical trials in patients with HFpEF so far have not produced clear-cut favorable results, and guidelines for patients with HFpEF do not suggest specific medications besides the control of symptoms using diuretics (Ponikowski et al., 2016). Women represent the majority of patients with HFpEF. Although the reason for the sex-differences in HFpEF are not well known, one of the causes could be the activation of 
the renin-angiotensin-aldosterone system after menopause (Yanes et al., 2010). Accordingly, MRA treatment may be more efficacious in women than in men regarding CV effects (Khosla et al., 2009). MRAs are of particular interest in the treatment of HFpEF due to their effects on interstitial fibrosis, myocardial stiffness, extracellular matrix expansion and vascular function, which are all key components in the pathogenesis of HFpEF.

The Aldo-DHF randomized controlled trial (Effects of Spironolactone on Diastolic Function and Exercise Capacity in Patients with Heart Failure with Preserved Ejection Fraction) demonstrated that treatment with spironolactone improved diastolic dysfunction and reduced blood pressure in HFpEF patients, however, maximal exercise capacity and symptoms were not significantly altered (Edelmann et al., 2013). A larger study, the TOPCAT trial (Treatment of Preserved Cardiac Function Heart Failure with an Aldosterone Antagonist) showed that spironolactone treatment promoted a decrease in hospitalization but not in mortality in HFpEF patients (Pitt et al., 2014; de Denus et al., 2017). Interestingly, a significant interaction between sex and MRA treatment has been described based on the reduction in all-cause mortality in women (Merrill et al., 2019). In a secondary analysis of TOPCAT, spironolactone in patients with HFpEF and resistant hypertension decreased the risk of composite CV events, whereas this was not the case in those without resistant hypertension (Tsujimoto and Kajio, 2020). In addition, spironolactone use in patients with HFpEF with resistant hypertension led to a decreased risk of all-cause death and hospitalization for HF. These results support the recommendation to use spironolactone in patients with hypertension resistant to standard medical treatment (Williams et al., 2018).

In a meta-analysis of 14 randomized controlled clinical trials, which included 6428 patients with HFpEF or MI with preserved ejection fraction, MRA therapy reduced the number of hospitalizations for HF by $17 \%$, improved diastolic function, induced a reversal of cardiac remodeling and improved quality of life, but did not decrease all-cause mortality (Chen et al., 2015). Another meta-analysis including 11 studies, evaluated the effects of MRAs on LV structure and function among patients with diastolic dysfunction or HFpEF. MRA therapy in patients with asymptomatic diastolic dysfunction or HFpEF was associated with significant improvement in diastolic function, blood pressure, and markers of cardiac fibrosis without a significant change in LV mass or dimensions (Pandey et al., 2015).

In the STRUCTURE trial (Spironolactone in Myocardial Dysfunction with Reduced Exercise Capacity), spironolactone therapy significantly improved the exercise capacity in patients with HFpEF and abnormal diastolic response to exertion. The authors suggested that identification of an elevated LV filling pressure induced by exercise in subjects with HFpEF may select out a subgroup of patients with a higher likelihood of a beneficial response to spironolactone (Kosmala et al., 2016).

More recently, canrenone was supported for the management of congestive HF and preserved systolic function by the COFFEE-IT trial (Canrenone Effects on Cardiovascular Mortality in Patients With Congestive Heart Failure), which found an improvement in mortality with the additional use of canrenone compared with the conventional therapy group (Derosa et al., 2019). Investigators found that patients on canrenone displayed a decreased LV mass compared with the control group, as well as a decreased mortality in patients within the 68-83-year age range after 10 years of follow-up. Despite these positive findings, canrenone is not widely used.

Another study including HFpEF and HF with mid-range EF (HFmrEF) patients suggested a benefit from spironolactone treatment, showing reduced hospitalizations and BNP levels, improved NYHA functional class, alleviated myocardial fibrosis by decreasing serum collagen type I marker in HFmrEF and HFpEF, and decreased collagen type III marker levels only in HFpEF (Xiang et al., 2019).

Currently, three ongoing large trials investigate MRA treatment in patients with HFpEF. SPIRIT-HF (SPIRonolactone In the Treatment of Heart Failure; NCT04727073; EudraCT 2017-000697-11) compares spironolactone to placebo in reducing recurrent HF hospitalizations and CV death in HF patients (NYHA II-IV) with mid-range or preserved ejection fraction. The SPIRRIT trial (Spironolactone Initiation Registry Randomized Interventional Trial in Heart Failure With Preserved Ejection Fraction; NCT02901184) aims at investigating 
whether spironolactone compared to standard of care alone reduces the composite of CV mortality and HF hospitalization. Complementarily, the FINEARTS-HF trial (Study to Evaluate the Efficacy and Safety of Finerenone on Morbidity and Mortality in Participants With Heart Failure and Left Ventricular Ejection Fraction Greater or Equal to 40\%, NCT04435626) has been designed to evaluate the effect of finerenone compared to placebo in the reduction of CV death and total HF events in HFpEF and HFmrEF patients. In patients with diabetic kidney disease without history of HFrEF in the FIDELIO-DKD trial (Finerenone in Reducing Kidney Failure and Disease Progression in Diabetic Kidney Disease), finerenone recently has been shown to reduce both a composite of renal events and a composite of CV events with an acceptable side-effect profile in this vulnerable patient population (Bakris et al., 2020).

Acute myocardial infarction

Based on the results from the EPHESUS study, the REMINDER trial (Impact Of Eplerenone On Cardiovascular Outcomes In Patients Post Myocardial Infarction) demonstrated that eplerenone administration during the acute phase of STEMI in patients without HF was safe and well tolerated, and associated with improvement in the primary outcome (mainly driven by a reduction in BNP/NT-proBNP levels at follow-up). There was a trend towards a greater benefit when eplerenone was administrated at 6 hours (Montalescot et al., 2014). Interestingly, eplerenone reduced collagen type III peptide levels. This may limit extracellular matrix formation in post-MI patients without HF, contributing to the clinical benefits of this therapy (Ferreira et al., 2018). However, the ALBATROSS randomized clinical trial (Aldosterone Lethal Effects Blockade in Acute Myocardial Infarction Treated With or Without Reperfusion to Improve Outcome and Survival at Six Months Follow-up) failed to show a benefit of canrenoate/spironolactone treatment initiated early in patients with acute MI (including STEMI and NSTEMI) without HF. Nevertheless it reported a reduction of mortality only in the ST-segment elevation MI subgroup (Beygui et al., 2016). It is important to highlight that both REMINDER and ALBATROSS were underpowered to detect treatment effect differences in morbidity and mortality. However, in a pre-specified meta-analysis of patient-level data of the STEMI patients from both studies, MRA treatment in acute STEMI was associated with a reduction of death, and death or resuscitated sudden death (Beygui et al., 2018).

The MINIMIZE STEMI trial (MR antagonist pre-treatment and early post-treatment to minimize reperfusion injury after ST-elevation myocardial infarction) did not show a benefit of canrenoate or spironolactone therapy in reducing MI size when applied prior to reperfusion, but there was an improvement on LV remodeling at 3 months in STEMI patients without HF (Bulluck et al., 2019).

\section{Acute heart failure}

MRA efficacy has also been investigated in patients with acute HF. The ATHENEA-HF trial (Efficacy and safety of spironolactone in acute HF) showed that the addition of high dose spironolactone to usual care for patients with acute HF did not change NT-proBNP levels and did not improve symptoms, congestion and clinical outcomes (Butler et al., 2017). Moreover, concentrations of spironolactone and its metabolites were measured in patients receiving high doses of spironolactone, showing that these concentrations were lower than anticipated (de Denus et al., 2020). Furthermore, the EARLIER trial (Efficacy and Safety of Early Initiation of Eplerenone Treatment in patients with acute HF) demonstrated that although the early initiation of eplerenone treatment in acute $\mathrm{HF}$ patients was safe, the incidence of $\mathrm{CV}$ death or re-hospitalization was not reduced (Asakura et al., 2020).

\section{Cellular studies}

Results from the clinical trials demonstrated the beneficial effect of MR antagonism in HFrEF and in HFpEF. MRA therapy could improve cardiac function, and reduce cardiac hypertrophy, inflammation, fibrosis, arterial stiffness or endothelial dysfunction. Already after the publication of the RALES study in 1999, in parallel to the subsequent clinical studies with MRA, the markedly beneficial results led researchers to perform numerous basic and translational studies focusing on the analysis of MR expression and activation in cells of the CV system. 


\section{Cardiomyocytes}

Cardiomyocyte MR plays a role in regulating cardiac function, electrical conduction and fibrosis, through direct signal mediation and through paracrine MR-dependent activity. In neonatal rat cardiomyocytes, aldosterone induces expression of angiotensin-converting enzyme via MR, creating a vicious circular cascade involving the renin-angiotensin-aldosterone-system (Harada et al., 2001). Long-time aldosterone exposure induces cardiomyocyte hypertrophy, this effect being suppressed by eplerenone (Yamamuro et al., 2006). Moreover, MR activation by aldosterone led to an increase in the hypertrophic and pro-inflammatory cytokine cardiotrophin-1 (CT-1) in adult HL-1 cardiomyocytes, suggesting CT-1 as a possible mediator of cardiomyocyte growth (López-Andrés et al., 2008). Finally, CD14, a ligand of TLR4 (toll-like receptor-4), has been proposed as a mediator of the chronotropic effects of the aldosterone/MR pathway activation in cardiomyocytes (Mannic et al., 2015). Thus, MR activation plays a central role in cardiomyocyte hypertrophy.

\section{Cardiac fibroblasts}

MR activation induced an up-regulation in collagen synthesis in rat cardiac fibroblasts (Brilla et al., 1994; Zhou et al., 1996) as well as collagen type I, collagen type III and collagen type VI expressions in adult human cardiac fibroblasts (Martínez-Martínez et al., 2017b). The mechanisms that mediates aldosterone/MRinduced collagen accumulation involved the increase in the pro-inflammatory and pro-fibrotic molecule galectin-3 (Gal-3) (Martínez-Martínez et al., 2015), the induction of tissue inhibitor of metalloproteinases-1 (TIMP-1) expression (Hung et al., 2016), or the augmentation of neutrophil gelatinase-associated lipocalin (NGAL) (Martínez-Martínez et al., 2017a). Moreover, using a quantitative proteomic approach, A kinase anchoring protein (AKAP)-12 was identified as a mediator of aldosterone/MR-induced oxidative stress in human cardiac fibroblasts that leads to mitochondrial dysfunction (Ibarrola et al., 2018). Taken together, these findings support the involvement of cardiac fibroblast-MR pathway activation in fibrosis and oxidative stress.

\section{Vascular smooth muscle cells}

The MR is involved in the activation of numerous signaling pathways in vascular smooth muscle cells (VSMCs) including extracellular signal-regulated kinase (ERK), mitogen-activated protein kinase (MAPK), the tyrosine kinase c-Src, c-jun $\mathrm{N}$ terminal kinase (JNK), epidermal growth factor receptor (EGFR) or myosin phosphate target subunit-1 (MYPY1), leading to VSMC stress fiber formation, migration, inflammation and oxidative stress (Mazak et al., 2004; Callera et al., 2005a, 2005b; Miyata et al., 2008; Cai et al., 2017). Of special interest, aldosterone mediated by MR activation increased the expression of Gal-3 in a dose- and time-dependent manner in VSMCs (Calvier et al., 2013). Gal-3, via its lectin activity, emerged as an essential factor allowing aldosterone/MR-induced vascular inflammation and fibrosis in vitro (Calvier et al., 2013). In summary, MR activation in VSMCs leads to inflammation, oxidative stress and fibrosis.

\section{Endothelial cells}

In human coronary endothelial cells, aldosterone specifically enhanced intercellular adhesion molecule (ICAM)-1 and promoted leukocyte adhesion via MR (Caprio et al., 2008). In addition to inflammation, aldosterone induced superoxide generation through NADPH oxidase activation in an MR-dependent manner in endothelial cells (Iwashima et al., 2008). Moreover, aldosterone-induced anti-angiogenic effects in endothelial cells were dependent on MR activation (Lother et al., 2018b). Aldosterone also increased endothelial cell volume through an MR-dependent mechanism (Oberleithner et al., 2003, 2006), resulting in increased stiffness of endothelial cells, MR-dependent cell growth (Hillebrand et al., 2007), and reduced nitric oxide (NO) release (Oberleithner et al., 2007). Altogether, these results show that aldosterone/MR pathway exerts a direct effect on endothelial cells enhancing inflammation, oxidative stress, anti-angiogenesis and influencing their mechanical and functional properties.

\section{Cardiac valve cells}

Recently, it has been demonstrated that MR pathway regulates the phenotypic, molecular, and histological changes of valve interstitial cells (VICs) and valve endothelial cells (VECs) (Ibarrola et al., 2020b). In VICs, 
the effects of aldosterone/MR activation were mediated by CT-1, whereas the effects of the mineralocorticoid were mediated by CD14 in VECs. Thus, VIC activation, endothelial-mesenchymal transition and proteoglycan deposition seem to be MR-dependent mechanisms (Ibarrola et al., 2020b). Moreover, MRA treated patients with mitral valve prolapse displayed lower levels of proteoglycans in the mitral valves. Altogether, MRA treatment appears to be a promising option to reduce fibromyxomatous alterations in patients with mitral valve prolapse (Ibarrola et al., 2020b).

\section{Inflammatory cells}

Classically activated macrophages, also called M1 macrophages, contribute to tissue inflammation, oxidative stress, and damage. Macrophages can be alternatively activated to the M2 phenotype that is involved in fibrosis and tissue remodeling. In vitro, using cultured thioglycolate-elicited mouse peritoneal macrophages, MR activation resulted in increased expression of the M1 classical activation markers (Usher et al., 2010). Complementarily, MR-deficient macrophages showed reduced expression of M1 markers and a shift towards the alternative-activated M2 phenotype (Usher et al., 2010). MR activation by aldosterone induced the activation of dendritic cells and increased polarization of CD4+ naive T cells into Th17, Th1, and decreased Treg cells (Herrada et al., 2010; Caillon et al., 2019). Aldosterone also increases the recruitment of B lymphocytes and the activation of CD8+ T cells via MR. Interestingly, aldosterone induced Gal-3 expression through MR in a human monocyte cell line and in a mouse macrophage cell line (Lin et al., 2014). Thus, there is a role for MR in macrophage polarization as well as in dendritic B and T cells activation.

\section{Animal models}

To further evidence the role of MR activation and the beneficial effects of MR blockade in CV diseases in more detail, researchers performed classical experiments employing MRA in pathological animal models (Riehle and Bauersachs, 2019), and also created dedicated mice with cell-specific MR deletion or overexpression. The study of these models has allowed analyzing the cellular and molecular mechanisms underlying the beneficial effects of MR blockade and has led to the identification of new potential pharmacological targets in the aldosterone/MR system.

\section{Pharmacological MR blockade in pathological animal models}

The available MRAs include the non-selective steroidal MRA spironolactone that also displays hormonal side-effects like gynaecomastia. Eplerenone, a newer steroidal MRA, is more selective than spironolactone. Novel non-steroidal MRA are totally different from the clinically available steroidal MRA, with finerenone being the most intensely studied holding the promise of beneficial CV and renal effects with lower rates of hyperkalemia and negligible hormonal side-effects (Kolkhof and Bärfacker, 2017; Agarwal et al., 2021).

\section{Hypertensive models}

MRAs have been widely used in hypertensive models, highlighting its beneficial effects in CV fibrosis, oxidative stress and inflammation. These experimental models include aldosterone-salt, deoxycorticosterone acetate (DOCA)-salt or angiotensin II treatments, thoracic aortic constriction or spontaneously hypertensive rats. The vast majority of studies have been conducted in aldosterone-salt-challenged animals co-treated with MRA and have focused on adverse vascular and cardiac remodeling and dysfunction. Increased oxidative stress and vascular inflammation are the first effects of aldosterone in vessels, being vascular inflammation partly dependent on oxidative stress (Sun et al., 2002).

Spironolactone prevented aldosterone-salt-induced oxidative stress as well as vascular infiltration of monocytes, macrophages, and lymphocytes in mice (Kasal et al., 2012) and rats (Nakano et al., 2005). Regarding vascular function, eplerenone blunted the aldosterone-induced increase in large artery stiffness, pulse pressure and the carotid elastic modulus (Lacolley et al., 2002). Spironolactone reduced cardiac inflammation and oxidative stress induced by aldosterone treatment (Sun et al., 2002) and eplerenone prevented aldosteronedependent cardiac fibrosis (Nebme et al., 2006).

Spironolactone decreased cardiac fibrosis by blocking the activation of $\mathrm{T}$ Helper 17 and the downregulation 
of regulatory $\mathrm{T}$ lymphocytes in DOCA-salt rats (Amador et al., 2014), suggesting that $\mathrm{T}$ cells could be involved in aldosterone-induced oxidative stress, because DOCA acts through MR (Guzik et al., 2007).

In angiotensin II-dependent models, spironolactone improved vascular changes and oxidative stress (Virdis et al., 2002), and blocked the hypertensive effects as well as the cardiac fibrosis and oxidative stress (Johar et al., 2006). Using angiotensin II overproducing transgenic mice, the protective effect of spironolactone against hypertensive vascular hypertrophy and remodeling has also been proved (Sakurabayashi-Kitade et al., 2009).

In line with these findings, eplerenone decreased myocardial oxidative stress, fibrosis and inflammation, limiting the transition to HF in a pressure-overload mice model (Kuster et al., 2005). In spontaneously hypertensive rats, early spironolactone treatment also decreased HF development by improving myocardial systolic and diastolic function, and attenuating hypertrophy and fibrosis (Cezar et al., 2015).

Treatment with spironolactone also prevented diet-induced diastolic dysfunction and arterial stiffness in female mice (De Marco et al., 2015). Finerenone improved HFpEF by decreasing LV filling pressure, increasing LV compliance, and prevented coronary endothelial dysfunction in ovariectomized mice (Pieronne-Deperrois et al., 2021).

\section{Myocardial infarction models}

Eplerenone improved LV remodeling in rats with LV dysfunction after extensive MI (Fraccarollo et al., 2003). These results were confirmed by Wang and colleagues, showing that eplerenone attenuated the cardiac remodeling and improved the cardiac function in a mouse model of HF after MI (Wang et al., 2004). Moreover, immediate MR blockade with eplerenone after MI in mice induced a more rapid accumulation of monocytes and accelerated macrophage infiltration leading to cytokine production. The cytokine cascade contributed to the vicious circle by recruiting and activating inflammatory cells that finally promoted an increase in neovascularization, leading to a reduced expansion of the healing process and improving early LV dilation and dysfunction (Fraccarollo et al., 2008). Interestingly, eplerenone exhibited a superior efficacy compared with spironolactone during the acute phase of MI (Fraccarollo et al., 2015). Finerenone also exerted beneficial effects after MI by the improvement of LV dysfunction, likely through the maintenance of the coronary reserve and improvement of coronary endothelial function (Gueret et al., 2016).

\section{Heart valve disease models}

The information regarding the role of MR in cardiac valve physiology or pathology is scarce. The lack of relevant experimental models of human valve diseases makes it difficult to study the potential benefits of pharmacological treatments. In the context of aortic valve diseases, spironolactone reduced myocardial fibrosis and LV mass in rodents with chronic aortic regurgitation, although aortic valve alterations have not been explored (Adnane Zendaoui et al., 2012). In a model of aortic stenosis-induced chronic LV pressureoverload, early administration of spironolactone unexpectedly increased cardiac hypertrophy and dilation, and impaired LV function (Okoshi et al., 2016).

Anorectic compounds, including nordexfenfluramine (NDF) that interact with the serotonergic system by targeting 5-HT2 (5-hydroxytryptamine receptor) receptor subtypes have been associated with fibromyxomatous remodeling of the mitral valve (HM et al., 1997). Pharmacological intervention using spironolactone prevented the increase in the area and thickness of mitral valve leaflets, as well as the increased expression of mitral valve proteoglycans in NDF-treated mice (Ibarrola et al., 2020b). Moreover, spironolactone also exerted beneficial effects in myocardium by reducing fibrosis (Ibarrola et al., 2020a). In accordance with these findings, the addition of spironolactone to conventional therapy increased survival compared with treatment with conventional therapy alone in dogs with naturally occurring myxomatous mitral valve disease (Bernay et al., 2010).

\section{Mice models with cell-specific MR deletion or overexpression}

The generation of mice with cell-selective MR ablation or overexpression have contributed to the knowledge of the specific roles of MR-mediated cell signaling in normal physiology and in pathological conditions 
(Bauersachs et al., 2015; Young and Rickard, 2015). The use of specific animal models in which the expression of MR is cell-dependently blocked or overexpressed, helps to understand the role of MR in CV diseases. These experimental models associate hypertension, cardiac hypertrophy, and the development of ventricular fibrosis, revealing the harmful CV impact of cell-specific MR activation or repression.

Cardiomyocyte MR overexpression

Overexpression of MR in the heart resulted in dilated cardiomyopathy (Le Menuet et al., 2001). Mice overexpressing cardiac MR did not show increased cardiac fibrosis, inflammation or apoptosis (Latouche et al., 2012). However, cardiac specific MR overexpression in mice induced an increase in sudden cardiac death (Ouvrard-Pascaud et al., 2005). Mice overexpressing MR in cardiomyocytes present increased levels of the pro-fibrotic factor connective tissue growth factor (CTGF) (Messaoudi et al., 2013) as well as of NGAL (Latouche et al., 2012). As mentioned above, NGAL is a critical mediator of the pro-fibrotic and proinflammatory effects of aldosterone/MR activation (Tarjus et al., 2015; Martínez-Martínez et al., 2017a). Interestingly, NGAL inactivation protected mice against adverse myocardial remodeling after MI (MartínezMartínez et al., 2017a).

\section{Cardiomyocyte MR deficient model}

There is strong evidence that specific MR blockade in cardiomyocytes exerts beneficial effects against pathological conditions. Mice lacking specifically cardiomyocyte MR presented cardiac hypertrophy accompanied by distinct changes in myocytes gene expression, with normal systolic and diastolic functions (Lother et al., 2011). Moreover, under pathological conditions, selective cardiomyocyte MR deficiency improved infarct healing and protected against progressive adverse remodeling and molecular alterations (Fraccarollo et al., 2011). Cardiomyocyte-specific inactivation of MR accelerated inflammation and endothelial cell response of wound repair, as well as enhanced infarct neovascularization. Cardiomyocyte MR deficient mice also presented a reduction in cardiac oxidative stress, fibrosis and apoptosis. All the above molecular and histological features contributed to a reduced infarct expansion, LV dilation and myocardial wall stress, leading to an improvement in cardiac remodeling, contractile dysfunction and HF (Fraccarollo et al., 2011).

MR cardiomyocyte-null mice treated with DOCA/salt were protected from cardiac fibrosis and inflammation (Rickard et al., 2012). Interestingly, cardiomyocyte MR ablation protected mice from cardiac dilation and failure but did not protect against cardiac hypertrophy, fibrosis, apoptosis or inflammation after chronic pressure overload (Lother et al., 2011). In line with these findings, cardiomyocyte MR deletion prevented doxorubicin-induced LV dysfunction but did not protect from myocardial fibrosis (Lother et al., 2018a).

\section{Fibroblast MR deletion}

Against the common believe that MR activation in fibroblasts essentially contributes to LV remodeling, cell-specific fibroblast MR-null mice were not protected against pressure overload-induced cardiac fibrosis and dysfunction (Lother et al., 2011). Also in an animal model of pulmonary hypertension, fibroblast-specific MR knockout was not protective against pulmonary vascular remodeling (Kowalski et al., 2021).

Vascular smooth muscle cell MR deficient models

Arterial stiffening is associated with altered arterial function with decreased distensibility and modified wall structure contributing to HF development (Lacolley et al., 2009). Moreover, VSMC MR regulated hypertensive responses to vasoactive substances, vascular contractility and oxidative stress (McCurley et al., 2012). Selective VSMC MR deficient mice exhibited lower blood pressure. Aldosterone-salt treatment did not modify arterial stiffness in mice with VSMC-specific MR deletion, suggesting that vascular smooth muscle MR may be required to adapt arterial stiffness to stress (Galmiche et al., 2014). Accordingly, VSMCsrestricted MR deficiency protected from aldosterone-induced vascular fibrosis (Pruthi et al., 2014). Moreover, specific deletion of MR in VSMCs improved LV dysfunction and remodeling after MI in a similar proportion than finerenone (Gueret et al., 2016). Cell-specific MR ablation in VSMCs also improved cardiac blood supply in a pressure-overload model and diminished the adverse cardiac remodeling and cardiac dilation (Kim et al., 2021). 
Specific MR loss in VSMCs led to lower blood pressure levels in aged mice (McCurley et al., 2012) and decreased the expression of pro-fibrotic genes in the aging vasculature (Kim et al., 2018). Moreover, longterm treatment of aged mice with MR antagonist prevented the progression of vascular stiffening, reduced vascular fibrosis and induced a similar anti-fibrotic gene signature as VSMC-MR gene deletion (Kim et al., 2018).

\section{Endothelial cell MR deficient models}

Blocking specifically MR in endothelial cells protected against aldosterone-impaired endothelial function only in aorta (not in resistance arteries) (Rickard et al., 2014). Moreover, endothelial cell MR-knockout mice presented reduced cardiac fibrosis and inflammation in the absence of blood pressure reduction when treated with DOCA/salt (Rickard et al., 2014). Endothelial MR deletion improved capillary density in DOCA-treated mice (Lother et al., 2018b). Selective MR deletion in endothelial cells protected from the decline in systolic function in response to thoracic aortic constriction (Salvador et al., 2017). NDF failed to increase mitral valve area, thickness, or proteoglycan content in mice specifically lacking endothelial MR expression (Ibarrola et al., 2020b). MR deletion in endothelial cells decreased the endothelial dysfunction in obese female mice (Davel et al., 2018). Selective endothelial cells MR deficient mice were protected against obesity-induced endothelial dysfunction (Schäfer et al., 2013). Endothelial cell-specific MR ablation also improved hypoxiainduced pulmonary vascular remodeling to a similar extent as did eplerenone treatment (Kowalski et al., 2021).

\section{Endothelial cell MR overexpression model}

Endothelial cell-restricted overexpression of the MR increased the contractile response of mesenteric arteries and increased blood pressure in response to hypertensive agents (Cat et al., 2010). Endothelial cell-specific MR overexpression in mice reduced atrial thrombus formation after ferric chloride injury (Lagrange et al., 2014) suggesting a role for endothelial cell MR as an antithrombotic factor.

\section{Macrophage MR deficient model}

Monocytes/macrophages play an important role in the clearance of apoptotic cells, the release of cytokines, proteases and the modulation of oxidative stress, contributing to wound repair process (Weinberger and Schulz, 2015). Myeloid MR is a key regulator of CV inflammation, fibrosis and hypertrophy (Rickard et al., 2009; Usher et al., 2010; Fraccarollo et al., 2011). Thus, macrophage-specific MR-null mice exhibited an altered expression of pro-inflammatory molecules (Rickard and Young, 2009; Usher et al., 2010; Bienvenu et al., 2012). MR deletion in macrophages protected against L-NAME/angiotensin II-induced cardiac hypertrophy, cardiac and vascular macrophage recruitment, inflammation and fibrosis (Usher et al., 2010). Myeloid cell-restricted MR deficiency led to improved healing and cardiac remodeling after ischemic injury trough the promotion of neutrophil efferocytosis, the suppression of superoxide production and the modulation of fibroblasts activation (Fraccarollo et al., 2019). MR knock-out prevented the upregulation of NGAL in infarct macrophages. Genetic ablation of myeloid MR reduced infarct size and inflammation after transient middle cerebral artery occlusion, whereas myeloid MR-knockout mice were not protected from permanent middle cerebral artery occlusion (Frieler et al., 2012). These studies using specific macrophage MR-null mice highlight that MR signaling in the myeloid cell population is essential for the pro-inflammatory and pro-fibrotic CV phenotype.

\section{Conclusions}

While initially MR expression was thought to be restricted to kidney epithelial cells, numerous translational studies have shed light on the complex (patho-)physiological importance of MR expression in many CV cells such as cardiomyocytes, endothelial cells and VSMCs. MRA are an essential part of medical therapy for HF and resistant hypertension for many years. Currently the novel non-steroidal MRA finerenone is introduced into clinical practice for patients with diabetic kidney disease to reduce both progression of renal disease and CV events.

\section{Conflict of interest}


J.B. reports personal fees from Novartis, Vifor, Bayer, Servier, Abiomed, Pfizer, Boehringer Ingelheim, AstraZeneca, Cardior, Daichii Sankyo, CVRx, BMS, MSD, Amgen, Corvia; grants: Zoll, CVRx, Vifor, Abiomed; all outside the submitted work.

\section{Figures legends}

Figure 1. Effects of mineralocorticoid receptor (MR) activation in cells involved in cardiovascular (patho)physiology.

MR, mineralocorticoid receptor; VSMC, vascular smooth muscle cell; VIC, valve interstitial cell; VEC, valve endothelial cell.

Figure 2. Animal models with cell-specific modulation of the mineralocorticoid receptor (MR).

MR, mineralocorticoid receptor; VSMC, vascular smooth muscle cell; DOCA, deoxycorticosterone acetate; L-NAME, L-NG-Nitroarginine Methyl Ester; NDF, nordexfenfluramine.

\section{References}

Adnane Zendaoui, Dominic Lachance, Elise Roussel, Jacques Couet, and Marie Arsenault (2012). Effects of spironolactone treatment on an experimental model of chronic aortic valve regurgitation - PubMed.21 : $478-486$.

Agarwal, R., Kolkhof, P., Bakris, G., Bauersachs, J., Haller, H., Wada, T., et al. (2021). Steroidal and non-steroidal mineralocorticoid receptor antagonists in cardiorenal medicine. Eur. Heart J. 42 : 152-161.

Amador, C.A., Barrientos, V., Peña, J., Herrada, A.A., González, M., Valdés, S., et al. (2014). Spironolactone decreases DOCA-salt-induced organ damage by blocking the activation of $\mathrm{T}$ helper 17 and the downregulation of regulatory T lymphocytes. Hypertension $63: 797-803$.

Asakura, M., Ito, S., Yamada, T., Saito, Y., Kimura, K., Yamashina, A., et al. (2020). Efficacy and Safety of Early Initiation of Eplerenone Treatment in Patients with Acute Heart Failure (EARLIER trial): a multicentre, randomized, double-blind, placebo-controlled trial. Eur. Hear. J. - Cardiovasc. Pharmacother. 11;pvaa132.

Bakris, G.L., Agarwal, R., Anker, S.D., Pitt, B., Ruilope, L.M., Rossing, P., et al. (2020). Effect of Finerenone on Chronic Kidney Disease Outcomes in Type 2 Diabetes. N. Engl. J. Med. 383 : 2219-2229.

Bauersachs, J., Jaisser, F., and Toto, R. (2015). Mineralocorticoid receptor activation and mineralocorticoid receptor antagonist treatment in cardiac and renal diseases. Hypertension $65: 257-263$.

Berliner, D., Hänselmann, A., and Bauersachs, J. (2020). The treatment of heart failure with reduced ejection fraction. Dtsch. Arztebl. Int.117: 376-386.

Bernay, F., Bland, J.M., Häggström, J., Baduel, L., Combes, B., Lopez, A., et al. (2010). Efficacy of spironolactone on survival in dogs with naturally occurring mitral regurgitation caused by myxomatous mitral valve disease. J. Vet. Intern. Med. 24 : 331-341.

Beygui, F., Belle, E. Van, Ecollan, P., Machecourt, J., Hamm, C.W., Lopez De Sa, E., et al. (2018). Individual participant data analysis of two trials on aldosterone blockade in myocardial infarction. Heart104:1843-1849.

Beygui, F., Cayla, G., Roule, V., Roubille, F., Delarche, N., Silvain, J., et al. (2016). Early Aldosterone Blockade in Acute Myocardial Infarction the ALBATROSS Randomized Clinical Trial. J. Am. Coll. Cardiol. $67: 1917-1927$.

Bienvenu, L.A., Morgan, J., Rickard, A.J., Tesch, G.H., Cranston, G.A., Fletcher, E.K., et al. (2012). Macrophage mineralocorticoid receptor signaling plays a key role in aldosterone-independent cardiac fibrosis. Endocrinology $153: 3416-3425$. 
Bozkurt, B., Hershberger, R.E., Butler, J., Grady, K.L., Heidenreich, P.A., Isler, M.L., et al. (2021). 2021 ACC/AHA Key Data Elements and Definitions for Heart Failure: A Report of the American College of Cardiology/American Heart Association Task Force on Clinical Data Standards (Writing Committee to Develop Clinical Data Standards for Heart Failure). Circ. Cardiovasc. Qual. Outcomes 77 : 2053-2150.

Brilla, C.G., Zhou, G., Matsubara, L., and Weber, K.T. (1994). Collagen metabolism in cultured adult rat cardiac fibroblasts: Response to angiotensin II and aldosterone. J. Mol. Cell. Cardiol. 26 : 809-820.

Bulluck, H., Fröhlich, G.M., Nicholas, J.M., Mohdnazri, S., Gamma, R., Davies, J., et al. (2019). Mineralocorticoid receptor antagonist pre-treatment and early post-treatment to minimize reperfusion injury after ST-elevation myocardial infarction: The MINIMIZE STEMI trial. Am. Heart J. 211 : 60-67.

Butler, J., Anstrom, K.J., Felker, G.M., Givertz, M.M., Kalogeropoulos, A.P., Konstam, M.A., et al. (2017). Efficacy and safety of spironolactone in acute heart failure: The ATHENA-HF randomized clinical trial. JAMA Cardiol. 2 : 950-958.

Cai, W., Qiu, C., Zhang, H., Chen, X., Zhang, X., Meng, Q., et al. (2017). Detection of circulating natural antibodies to inflammatory cytokines in type-2 diabetes and clinical significance. J. Inflamm. (United Kingdom) $14: 24$.

Caillon, A., Paradis, P., and Schiffrin, E.L. (2019). Role of immune cells in hypertension. Br. J. Pharmacol. $176: 1818-1828$.

Callera, G.E., Montezano, A.C.I., Yogi, A., Tostes, R.C., He, Y., Schiffrin, E.L., et al. (2005a). c-Srcdependent nongenomic signaling responses to aldosterone are increased in vascular myocytes from spontaneously hypertensive rats. Hypertension $46: 1032-1038$.

Callera, G.E., Touyz, R.M., Tostes, R.C., Yogi, A., He, Y., Malkinson, S., et al. (2005b). Aldosterone activates vascular p38MAP kinase and NADPH oxidase via c-Src. In Hypertension, (Hypertension), pp 773-779.

Calvier, L., Miana, M., Reboul, P., Cachofeiro, V., Martinez-Martinez, E., Boer, R.A. De, et al. (2013). Galectin-3 mediates aldosterone-induced vascular fibrosis. Arterioscler. Thromb. Vasc. Biol.33 : 67-75.

Cannavo, A., Bencivenga, L., Liccardo, D., Elia, A., Marzano, F., Gambino, G., et al. (2018). Aldosterone and mineralocorticoid receptor system in cardiovascular physiology and pathophysiology. Oxid. Med. Cell. Longev. 2018 : 1204598.

Caprio, M., Newfell, B.G., Sala, A. La, Baur, W., Fabbri, A., Rosano, G., et al. (2008). Functional mineralocorticoid receptors in human vascular endothelial cells regulate intercellular adhesion molecule-1 expression and promote leukocyte adhesion. Circ. Res. 102 : 1359-1367.

Cat, A.N.D., Griol-Charhbili, V., Loufrani, L., Labat, C., Benjamin, L., Farman, N., et al. (2010). The endothelial mineralocorticoid receptor regulates vasoconstrictor tone and blood pressure. FASEB J. 24 : $2454-2463$.

Cezar, M.D.M., Damatto, R.L., Pagan, L.U., Lima, A.R.R., Martinez, P.F., Bonomo, C., et al. (2015). Early Spironolactone Treatment Attenuates Heart Failure Development by Improving Myocardial Function and Reducing Fibrosis in Spontaneously Hypertensive Rats. Cell. Physiol. Biochem.36 : 1453-1466.

Chen, Y., Wang, H., Lu, Y., Huang, X., Liao, Y., and Bin, J. (2015). Effects of mineralocorticoid receptor antagonists in patients with preserved ejection fraction: A meta-analysis of randomized clinical trials. BMC Med. $13: 10$.

Davel, A.P., Lu, Q., Moss, M.E., Rao, S., Anwar, I.J., DuPont, J.J., et al. (2018). Sex-specific mechanisms of resistance vessel endothelial dysfunction induced by cardiometabolic risk factors. J. Am. Heart Assoc. 7 : e007675.

Denus, S. de, Leclair, G., Dubé, M.P., St-Jean, I., Zada, Y.F., Oussaïd, E., et al. (2020). Spironolactone metabolite concentrations in decompensated heart failure: insights from the ATHENA-HF trial. Eur. J. 
Heart Fail. 22 : 1451-1461.

Denus, S. de, O’Meara, E., Desai, A.S., Claggett, B., Lewis, E.F., Leclair, G., et al. (2017). Spironolactone Metabolites in TOPCAT — New Insights into Regional Variation. N. Engl. J. Med. 376 : 1690-1692.

Derosa, G., Maffioli, P., Scelsi, L., Bestetti, A., Vanasia, M., Cicero, A.F.G., et al. (2019). Canrenone on cardiovascular mortality in congestive heart failure: CanrenOne eFFects on cardiovascular mortality in patiEnts with congEstIve hearT failure: The COFFEE-IT study. Pharmacol. Res. 141 : 46-52.

Edelmann, F., Wachter, R., Schmidt, A.G., Kraigher-Krainer, E., Colantonio, C., Kamke, W., et al. (2013). Effect of spironolactone on diastolic function and exercise capacity in patients with heart failure with preserved ejection fraction: The Aldo-DHF randomized controlled trial. JAMA - J. Am. Med. Assoc. 309 : $781-791$.

Ferreira, J.P., Barros, A., Pitt, B., Montalescot, G., Sa, E.L. de, Hamm, C.W., et al. (2018). Collagen biomarker bioprofiles predicting the antifibrotic response to eplerenone in myocardial infarction: findings from the REMINDER trial. Clin. Res. Cardiol. 107 : 1192-1195.

Filippatos, G., Anker, S.D., Böhm, M., Gheorghiade, M., Køber, L., Krum, H., et al. (2016). A randomized controlled study of finerenone vs. eplerenone in patients with worsening chronic heart failure and diabetes mellitus and/or chronic kidney disease. Eur. Heart J. 37 : 2105-2114.

Fraccarollo, D., Berger, S., Galuppo, P., Kneitz, S., Hein, L., Schütz, G., et al. (2011). Deletion of cardiomyocyte mineralocorticoid receptor ameliorates adverse remodeling after myocardial infarction. Circulation 123 : 400-408.

Fraccarollo, D., Galuppo, P., Hildemann, S., Christ, M., Ertl, G., and Bauersachs, J. (2003). Additive Improvement of Left Ventricular Remodeling and Neurohormonal Activation by Aldosterone Receptor Blockade with Eplerenone and ACE Inhibition in Rats with Myocardial Infarction. J. Am. Coll. Cardiol. 42 : 16661673 .

Fraccarollo, D., Galuppo, P., Schraut, S., Kneitz, S., Rooijen, N. Van, Ertl, G., et al. (2008). Immediate mineralocorticoid receptor blockade improves myocardial infarct healing by modulation of the inflammatory response. Hypertension 51 : 905-914.

Fraccarollo, D., Galuppo, P., Sieweke, J.T., Napp, L.C., Grobbecker, P., and Bauersachs, J. (2015). Efficacy of mineralocorticoid receptor antagonism in the acute myocardial infarction phase: eplerenone versus spironolactone. ESC Hear. Fail. 2 : 150-158.

Fraccarollo, D., Thomas, S., Scholz, C.J., Hilfiker-Kleiner, D., Galuppo, P., and Bauersachs, J. (2019). Macrophage Mineralocorticoid Receptor Is a Pleiotropic Modulator of Myocardial Infarct Healing. Hypertension $73: 102-111$.

Frieler, R.A., Ray, J.J., Meng, H., Ramnarayanan, S.P., Usher, M.G., Su, E.J., et al. (2012). Myeloid mineralocorticoid receptor during experimental ischemic stroke: effects of model and sex. J. Am. Heart Assoc. 1 : e002584.

Galmiche, G., Pizard, A., Gueret, A., Moghrabi, S. El, Ouvrard-Pascaud, A., Berger, S., et al. (2014). Smooth muscle cell mineralocorticoid receptors are mandatory for aldosterone-salt to induce vascular stiffness. Hypertension $63: 520-526$.

Gueret, A., Harouki, N., Favre, J., Galmiche, G., Nicol, L., Henry, J.P., et al. (2016). Vascular smooth muscle mineralocorticoid receptor contributes to coronary and left ventricular dysfunction after myocardial infarction. Hypertension $67: 717-723$.

Guzik, T.J., Hoch, N.E., Brown, K.A., McCann, L.A., Rahman, A., Dikalov, S., et al. (2007). Role of the $\mathrm{T}$ cell in the genesis of angiotensin II-induced hypertension and vascular dysfunction. J. Exp. Med.204 : 2449-2460. 
Harada, E., Yoshimura, M., Yasue, H., Nakagawa, O., Nakagawa, M., Harada, M., et al. (2001). Aldosterone induces angiotensin-converting-enzyme gene expression in cultured neonatal rat cardiocytes. Circulation 104 : 137-139.

Herrada, A.A., Contreras, F.J., Marini, N.P., Amador, C.A., González, P.A., Cortés, C.M., et al. (2010). Aldosterone Promotes Autoimmune Damage by Enhancing Th17-Mediated Immunity. J. Immunol. 184: 191-202.

Hillebrand, U., Schillers, H., Riethmüller, C., Stock, C., Wilhelmi, M., Oberleithner, H., et al. (2007). Dosedependent endothelial cell growth and stiffening by aldosterone: Endothelial protection by eplerenone. J. Hypertens. $25: 639-647$.

HM, C., JL, C., MD, M., DD, H., BS, E., WD, E., et al. (1997). Valvular heart disease associated with fenfluramine and phentermine. WHO Drug Inf. $11: 141$.

Hung, C.S., Chou, C.H., Liao, C.W., Lin, Y.T., Wu, X.M., Chang, Y.Y., et al. (2016). Aldosterone induces tissue inhibitor of metalloproteinases-1 expression and further contributes to collagen accumulation: From clinical to bench studies. Hypertension 67 : 1309-1320.

Ibarrola, J., Garaikoetxea, M., Garcia-Peña, A., Matilla, L., Jover, E., Bonnard, B., et al. (2020a). Beneficial effects of mineralocorticoid receptor antagonism on myocardial fibrosis in an experimental model of the myxomatous degeneration of the mitral valve. Int. J. Mol. Sci.21 : 1-13.

Ibarrola, J., Garcia-Peña, A., Matilla, L., Bonnard, B., Sádaba, R., Arrieta, V., et al. (2020b). A New Role for the Aldosterone/Mineralocorticoid Receptor Pathway in the Development of Mitral Valve Prolapse. Circ. Res. CIRCRESAHA.119.316427.

Ibarrola, J., Sadaba, R., Martinez-Martinez, E., Garcia-Peña, A., Arrieta, V., Alvarez, V., et al. (2018). Aldosterone Impairs Mitochondrial Function in Human Cardiac Fibroblasts via A-Kinase Anchor Protein. Sci. Rep. $8: 6801$.

Iwashima, F., Yoshimoto, T., Minami, I., Sakurada, M., Hirono, Y., and Hirata, Y. (2008). Aldosterone induces superoxide generation via Rac1 activation in endothelial cells. Endocrinology 149 : 1009-1014.

Johar, S., Cave, A.C., Narayanapanicker, A., Grieve, D.J., Shah, A.M., Johar, S., et al. (2006). Aldosterone mediates angiotensin II-induced interstitial cardiac fibrosis via a Nox2-containing NADPH oxidase. FASEB J. $20: 1546-1548$.

Kasal, D.A., Barhoumi, T., Li, M.W., Yamamoto, N., Zdanovich, E., Rehman, A., et al. (2012). T regulatory lymphocytes prevent aldosterone-induced vascular injury. Hypertension 59 : 324-330.

Khosla, N., Kalaitzidis, R., and Bakris, G.L. (2009). Predictors of hyperkalemia risk following hypertension control with aldosterone blockade. Am. J. Nephrol. 30 : 418-424.

Kim, S.K., Biwer, L.A., Moss, M.E., Man, J.J., Aronovitz, M.J., Martin, G.L., et al. (2021). Mineralocorticoid Receptor in Smooth Muscle Contributes to Pressure Overload-Induced Heart Failure. Circ. Heart Fail. 14 : e007279.

Kim, S.K., McCurley, A.T., DuPont, J.J., Aronovitz, M., Moss, M.E., Stillman, I.E., et al. (2018). Smooth muscle cell-mineralocorticoid receptor as a mediator of cardiovascular stiffness with aging. Hypertension 71 : 609-621.

Kolkhof, P., and Barfacker, L. (2017). Mineralocorticoid receptor antagonists: 60 years of research and development. J. Endocrinol.234 : T125-T140.

Kosmala, W., Rojek, A., Przewlocka-Kosmala, M., Wright, L., Mysiak, A., and Marwick, T.H. (2016). Effect of Aldosterone Antagonism on Exercise Tolerance in Heart Failure With Preserved Ejection Fraction. J. Am. Coll. Cardiol. 68 : 1823-1834. 
Kowalski, J., Deng, L., Suennen, C., Koca, D., Meral, D., Bode, C., et al. (2021). Eplerenone Improves Pulmonary Vascular Remodeling and Hypertension by Inhibition of the Mineralocorticoid Receptor in Endothelial Cells. Hypertension HYPERTENSIONAHA.120.16196.

Kuster, G.M., Kotlyar, E., Rude, M.K., Siwik, D.A., Liao, R., Colucci, W.S., et al. (2005). Mineralocorticoid receptor inhibition ameliorates the transition to myocardial failure and decreases oxidative stress and inflammation in mice with chronic pressure overload. Circulation $111: 420-427$.

Lacolley, P., Challande, P., Osborne-Pellegrin, M., and Regnault, V. (2009). Genetics and pathophysiology of arterial stiffness. Cardiovasc. Res. $81: 637-648$.

Lacolley, P., Labat, C., Pujol, A., Delcayre, C., Benetos, A., and Safar, M. (2002). Increased carotid wall elastic modulus and fibronectin in aldosterone-salt-treated rats: Effects of eplerenone. Circulation 106 : $2848-2853$.

Lagrange, J., Li, Z., Fassot, C., Bourhim, M., Louis, H., Nguyen Dinh Cat, A., et al. (2014). Endothelial mineralocorticoid receptor activation enhances endothelial protein $\mathrm{C}$ receptor and decreases vascular thrombosis in mice. FASEB J. $28: 2062-2072$.

Latouche, C., Moghrabi, S. El, Messaoudi, S., Cat, A.N.D., Hernandez-Diaz, I., La Rosa, D.A. De, et al. (2012). Neutrophil gelatinase-associated lipocalin is a novel mineralocorticoid target in the cardiovascular system. Hypertension $59: 966-972$.

Lin, Y.H., Chou, C.H., Wu, X.M., Chang, Y.Y., Hung, C.S., Chen, Y.H., et al. (2014). Aldosterone induced galectin-3 secretion in vitro and in vivo: From cells to humans. PLoS One 9 : e95254.

Lopez-Andres, N., Inigo, C., Gallego, I., Diez, J., and Fortuno, M.A. (2008). Aldosterone induces cardiotrophin-1 expression in HL-1 adult cardiomyocytes. Endocrinology 149 : 4970-4978.

Lother, A., Bergemann, S., Kowalski, J., Huck, M., Gilsbach, R., Bode, C., et al. (2018a). Inhibition of the cardiac myocyte mineralocorticoid receptor ameliorates doxorubicin-induced cardiotoxicity. Cardiovasc. Res. 114 : 282-290.

Lother, A., Berger, S., Gilsbach, R., Rosner, S., Ecke, A., Barreto, F., et al. (2011). Ablation of mineralocorticoid receptors in myocytes but not in fibroblasts preserves cardiac function. Hypertension 57 : $746-754$.

Lother, A., Deng, L., Huck, M., Furst, D., Kowalski, J., Esser, J.S., et al. (2018b). Endothelial cell mineralocorticoid receptors oppose VEGF-induced gene expression and angiogenesis. J. Endocrinol.240 : $15-26$.

Mannic, T., Satta, N., Pagano, S., Python, M., Virzi, J., Montecucco, F., et al. (2015). CD14 as a mediator of the mineralocorticoid receptor-dependent anti-apolipoprotein a-1 IgG chronotropic effect on cardiomyocytes. Endocrinology $156: 4707-4719$.

Marco, V.G. De, Habibi, J., Jia, G., Aroor, A.R., Ramirez-Perez, F.I., Martinez-Lemus, L.A., et al. (2015). Low-dose mineralocorticoid receptor blockade prevents western diet-induced arterial stiffening in female mice. Hypertension $66: 99-107$.

Martinez-Martinez, E., Buonafine, M., Boukhalfa, I., Ibarrola, J., Fernandez-Celis, A., Kolkhof, P., et al. (2017a). Aldosterone target NGAL (Neutrophil gelatinase-associated lipocalin) is involved in cardiac remod-

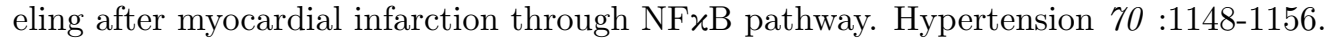

Martínez-Martínez, E., Calvier, L., Fernández-Celis, A., Rousseau, E., Jurado-López, R., Rossoni, L.V., et al. (2015). Galectin-3 blockade inhibits cardiac inflammation and fibrosis in experimental hyperaldosteronism and hypertension. Hypertension $66: 767-775$.

Martínez-Martínez, E., Ibarrola, J., Lachén-Montes, M., Fernández-Celis, A., Jaisser, F., Santamaría, E., et al. (2017b). Differential proteomics reveals S100-A11 as a key factor in aldosterone-induced collagen 
expression in human cardiac fibroblasts. J. Proteomics $166: 93-100$.

Mazak, I., Fiebeler, A., Muller, D.N., Park, J.K., Shagdarsuren, E., Lindschau, C., et al. (2004). Aldosterone potentiates angiotensin II-induced signaling in vascular smooth muscle cells. Circulation 109 : 2792-2800.

McCurley, A., Pires, P.W., Bender, S.B., Aronovitz, M., Zhao, M.J., Metzger, D., et al. (2012). Direct regulation of blood pressure by smooth muscle cell mineralocorticoid receptors. Nat. Med. 18 : 1429-1433.

Menuet, D. Le, Isnard, R., Bichara, M., Viengchareun, S., Muffat-Joly, M., Walker, F., et al. (2001). Alteration of Cardiac and Renal Functions in Transgenic Mice Overexpressing Human Mineralocorticoid Receptor. J. Biol. Chem. $276: 38911-38920$.

Merrill, M., Sweitzer, N.K., Lindenfeld, J.A., and Kao, D.P. (2019). Sex Differences in Outcomes and Responses to Spironolactone in Heart Failure With Preserved Ejection Fraction: A Secondary Analysis of TOPCAT Trial. JACC Hear. Fail. 7 : 228-238.

Messaoudi, S., Azibani, F., Delcayre, C., and Jaisser, F. (2012). Aldosterone, mineralocorticoid receptor, and heart failure. Mol. Cell. Endocrinol. 350 : 266-272.

Messaoudi, S., Gravez, B., Tarjus, A., Pelloux, V., Ouvrard-Pascaud, A., Delcayre, C., et al. (2013). Aldosterone-specific activation of cardiomyocyte mineralocorticoid receptor in vivo. Hypertension 61 : 361367.

Miyata, K., Hitomi, H., Guo, P., Zhang, G.X., Kimura, S., Kiyomoto, H., et al. (2008). Possible involvement of rho-kinase in aldosterone-induced vascular smooth muscle cell remodeling. Hypertens. Res. 31 : 1407-1413.

Montalescot, G., Pitt, B., Lopez De Sa, E., Hamm, C.W., Flather, M., Verheugt, F., et al. (2014). Early eplerenone treatment in patients with acute ST-elevation myocardial infarction without heart failure: The Randomized Double-Blind Reminder Study. Eur. Heart J. 35 : 2295-2302.

Nakano, S., Kobayashi, N., Yoshida, K., Ohno, T., and Matsuoka, H. (2005). Cardioprotective mechanisms of spironolactone associated with the angiotensin-converting enzyme/epidermal growth factor receptor/extracellular signal-regulated kinases, $\mathrm{NAD}(\mathrm{P}) \mathrm{H}$ oxidase/lectin-like oxidized low-density lipoprotein receptor-1, and Rho-kinase pathways in aldosterone/salt-induced hypertensive rats. Hypertens. Res. 28 : 925-936.

Nebme, J., Mercier, N., Labat, C., Benetos, A., Safar, M.E., Delcayre, C., et al. (2006). Differences between cardiac and arterial fibrosis and stiffness in aldosterone-salt rats: Effect of eplerenone. JRAAS - J. ReninAngiotensin-Aldosterone Syst. 7 : 31-39.

Oberleithner, H., Riethmüller, C., Ludwig, T., Hausberg, M., and Schillers, H. (2006). Aldosterone remodels human endothelium. In Acta Physiologica, (Acta Physiol (Oxf)), pp 305-312.

Oberleithner, H., Riethmüller, C., Schillers, H., MacGregor, G.A., Wardener, H.E. De, and Hausberg, M. (2007). Plasma sodium stiffens vascular endothelium and reduces nitric oxide release. Proc. Natl. Acad. Sci. U. S. A. $104: 16281-16286$.

Oberleithner, H., Schneider, S.W., Albermann, L., Hillebrand, U., Ludwig, T., Riethmüller, C., et al. (2003). Endothelial Cell Swelling by Aldosterone. J. Membr. Biol. 196 : 163-172.

Okoshi, M.P., Cezar, M.D.M., Iyomasa, R.M., Silva, M.B., Costa, L.C.O., Martinez, P.F., et al. (2016). Effects of early aldosterone antagonism on cardiac remodeling in rats with aortic stenosis-induced pressure overload. Int. J. Cardiol. 222 : 569-575.

Ouvrard-Pascaud, A., Sainte-Marie, Y., Bénitah, J.P., Perrier, R., Soukaseum, C., Cat, A.N.D., et al. (2005). Conditional mineralocorticoid receptor expression in the heart leads to life-threatening arrhythmias. Circulation $111: 3025-3033$. 
Pandey, A., Garg, S., Matulevicius, S.A., Shah, A.M., Garg, J., Drazner, M.H., et al. (2015). Effect of mineralocorticoid receptor antagonists on cardiac structure and function in patients with diastolic dysfunction and heart failure with preserved ejection fraction: A meta-analysis and systematic review. J. Am. Heart Assoc. 4 :e002137.

Pei, H., Wang, W., Zhao, D., Wang, L., Su, G.H., and Zhao, Z. (2018). The use of a novel non-steroidal mineralocorticoid receptor antagonist finerenone for the treatment of chronic heart failure: A systematic review and meta-analysis. Med. (United States) $97:$ e0254.

Pieronne-Deperrois, M., Guéret, A., Djerada, Z., Crochemore, C., Harouki, N., Henry, J.P., et al. (2021). Mineralocorticoid receptor blockade with finerenone improves heart function and exercise capacity in ovariectomized mice. ESC Hear. Fail. 8 :1933-1943.

Pitt, B., Pfeffer, M.A., Assmann, S.F., Boineau, R., Anand, I.S., Claggett, B., et al. (2014). Spironolactone for heart failure with preserved ejection fraction. N. Engl. J. Med. 370 : 1383-92.

Pitt, B., Remme, W., Zannad, F., Neaton, J., Martinez, F., Roniker, B., et al. (2003). Eplerenone, a Selective Aldosterone Blocker, in Patients with Left Ventricular Dysfunction after Myocardial Infarction. N. Engl. J. Med. $348: 1309-1321$.

Pitt, B., Zannad, F., Remme, W.J., Cody, R., Castaigne, A., Perez, A., et al. (1999). The Effect of Spironolactone on Morbidity and Mortality in Patients with Severe Heart Failure. N. Engl. J. Med. 341 : 709-717.

Ponikowski, P., Voors, A.A., Anker, S.D., Bueno, H., Cleland, J.G.F., Coats, A.J.S., et al. (2016). 2016 ESC Guidelines for the diagnosis and treatment of acute and chronic heart failure: The Task Force for the diagnosis and treatment of acute and chronic heart failure of the European Society of Cardiology (ESC). Developed with the special contribution of the Heart Failure Association (HFA) of the ESC. Eur. J. Heart Fail. $18: 891-975$.

Pruthi, D., Mccurley, A., Aronovitz, M., Galayda, C., Karumanchi, S.A., and Jaffe, I.Z. (2014). Aldosterone promotes vascular remodeling by direct effects on smooth muscle cell mineralocorticoid receptors. Arterioscler. Thromb. Vasc. Biol. 34 : 355-364.

Rickard, A.J., Morgan, J., Bienvenu, L.A., Fletcher, E.K., Cranston, G.A., Shen, J.Z., et al. (2012). Cardiomyocyte mineralocorticoid receptors are essential for deoxycorticosterone/salt-mediated inflammation and cardiac fibrosis. Hypertension $60: 1443-1450$.

Rickard, A.J., Morgan, J., Chrissobolis, S., Miller, A.A., Sobey, C.G., and Young, M.J. (2014). Endothelial cell mineralocorticoid receptors regulate deoxycorticosterone/ salt-mediated cardiac remodeling and vascular reactivity but not blood pressure. Hypertension 63 : 1033-1040.

Rickard, A.J., Morgan, J., Tesch, G., Funder, J.W., Fuller, P.J., and Young, M.J. (2009). Deletion of mineralocorticoid receptors from macrophages protects against deoxycorticosterone/salt-induced cardiac fibrosis and increased blood pressure. Hypertension 54 : 537-543.

Rickard, A.J., and Young, M.J. (2009). Corticosteroid receptors, macrophages and cardiovascular disease. J. Mol. Endocrinol. 42 : 449-459.

Riehle, C., and Bauersachs, J. (2019). Small animal models of heart failure. Cardiovasc. Res. 115 : 1838-1849.

Sakurabayashi-Kitade, S., Aoka, Y., Nagashima, H., Kasanuki, H., Hagiwara, N., and Kawana, M. (2009). Aldosterone blockade by Spironolactone improves the hypertensive vascular hypertrophy and remodeling in angiotensin II overproducing transgenic mice. Atherosclerosis $206: 54-60$.

Salvador, A.M., Moss, M.E., Aronovitz, M., Mueller, K.B., Blanton, R.M., Jaffe, I.Z., et al. (2017). Endothelial mineralocorticoid receptor contributes to systolic dysfunction induced by pressure overload without modulating cardiac hypertrophy or inflammation. Physiol. Rep.5 :e13313. 
Schäfer, N., Lohmann, C., Winnik, S., Tits, L.J. Van, Miranda, M.X., Vergopoulos, A., et al. (2013). Endothelialmineralocorticoid receptor activation mediates endothelial dysfunction in diet-induced obesity. Eur. Heart J. 34 : 3515-3524.

Sun, Y., Zhang, J., Lu, L., Chen, S.S., Quinn, M.T., and Weber, K.T. (2002). Aldosterone-induced inflammation in the rat heart: Role of oxidative stress. Am. J. Pathol. 161 : 1773-1781.

Tarjus, A., Martínez-Martínez, E., Amador, C., Latouche, C., Moghrabi, S. El, Berger, T., et al. (2015). Neutrophil gelatinase-associated lipocalin, a novel mineralocorticoid biotarget, mediates vascular profibrotic effects of mineralocorticoids. Hypertension $66: 158-166$.

Tsujimoto, T., and Kajio, H. (2020). Spironolactone Use and Improved Outcomes in Patients With Heart Failure With Preserved Ejection Fraction With Resistant Hypertension. J. Am. Heart Assoc. 9 : e018827.

Usher, M.G., Duan, S.Z., Ivaschenko, C.Y., Frieler, R.A., Berger, S., Schütz, G., et al. (2010). Myeloid mineralocorticoid receptor controls macrophage polarization and cardiovascular hypertrophy and remodeling in mice. J. Clin. Invest. 120:3350-3364.

Virdis, A., Neves, M.F., Amiri, F., Viel, E., Touyz, R.M., and Schiffrin, E.L. (2002). Spironolactone improves angiotensin-induced vascular changes and oxidative stress. Hypertension $40: 504-510$.

Wang, D., Liu, Y.H., Yang, X.P., Rhaleb, N.E., Xu, J., Peterson, E., et al. (2004). Role of a selective aldosterone blocker in mice with chronic heart failure. J. Card. Fail. $10: 67-73$.

Weinberger, T., and Schulz, C. (2015). Myocardial infarction: A critical role of macrophages in cardiac remodeling. Front. Physiol. 6 :107.

Williams, B., Mancia, G., Spiering, W., Rosei, E.A., Azizi, M., Burnier, M., et al. (2018). 2018 ESC/ESH Guidelines for themanagement of arterial hypertension. Eur. Heart J. 39 : 3021-3104.

Xiang, Y., Shi, W., Li, Z., Yang, Y., Wang, S.Y., Xiang, R., et al. (2019). Efficacy and safety of spironolactone in the heart failure with mid-range ejection fraction and heart failure with preserved ejection fraction: A meta-analysis of randomized clinical trials. Med. (United States) 98 :e14967.

Yamamuro, M., Yoshimura, M., Nakayama, M., Abe, K., Shono, M., Suzuki, S., et al. (2006). Direct effects of aldosterone on cardiomyocytes in the presence of normal and elevated extracellular sodium. Endocrinology 147 : 1314-1321.

Yanes, L.L., Romero, D.G., Iliescu, R., Zhang, H., Davis, D., and Reckelhoff, J.F. (2010). Postmenopausal hypertension: Role of the renin-angiotensin system. Hypertension $56: 359-363$.

Young, M.J., and Rickard, A.J. (2015). Mineralocorticoid receptors in the heart: Lessons from cell-selective transgenic animals. J. Endocrinol. 224 : R1-R13.

Zannad, F., Gattis Stough, W., Rossignol, P., Bauersachs, J., McMurray, J.J.V., Swedberg, K., et al. (2012). Mineralocorticoid receptor antagonists for heart failure with reduced ejection fraction: Integrating evidence into clinical practice. Eur. Heart J. 33 : 2782-2795.

Zannad, F., McMurray, J.J.V., Krum, H., Veldhuisen, D.J. van, Swedberg, K., Shi, H., et al. (2011). Eplerenone in Patients with Systolic Heart Failure and Mild Symptoms. N. Engl. J. Med. 364 : 11-21.

Zhou, G., Kandala, J.C., Tyagi, S.C., Katwa, L.C., and Weber, K.T. (1996). Effects of angiotensin II and aldosterone on collagen gene expression and protein turnover in cardiac fibroblasts. Mol. Cell. Biochem. 154 : 171-178.

\section{Hosted file}

Figures_FINAL.pptx available at https://authorea.com/users/423691/articles/528969mineralocorticoid-receptor-in-cardiovascular-diseases-clinical-trials-and-mechanisticinsights 